\title{
PERCEPÇÃO DA QUALIDADE SOCIOAMBIENTAL DA ÁREA URBANA DE ITABAIANA/SE
}

\author{
Clêane Oliveira dos Santos \\ Pós-Graduação em Geografia da Universidade Federal de Sergipe \\ Av. Marechal Rondon, s/nº, Jardim Rosa Elze, CEP 49100-000. São Cristovão (SE), Brasil \\ Tel: (55 79) 9948.0447 - cle.ufs@hotmail.com \\ Prof $^{\text {a }}$ Dra . Josefa Eliane Santana de Siqueira Pinto \\ josefaeliane@ufs.br
}

\begin{abstract}
RESUMO
O princípio norteador da presente pesquisa se contextualiza na perspectiva de que a intensificação da urbanização na modernidade causou problemas socioambientais na cidade do presente. A percepção ambiental é o foco central desta pesquisa na cidade de Itabaiana/SE, tendo como instrumentos de reflexão, registros observacionais envolvendo uma rede de implicações sociais, culturais e ambientais, complementados com questionários elaborados a luz de um referencial teórico específico. Itabaiana destaca-se na região de transição do agreste sergipano, parcialmente inserida no polígono das secas. Analisando os resultados, a população em xeque tem consciência da implicação de uma gestão imprópria dos resíduos sólidos com degradação na qualidade de vida, usufruem dos espaços arborizados de seus bairros e sentem-se mais incomodados com a poluição sonora e com a poluição do ar -fumaça - do que com a poluição da água, com a presença de esgotos e de lixeiras expostas.
\end{abstract}

Palavras-chave: Qualidade de vida, qualidade ambiental, percepção socioambiental.

\begin{abstract}
The guiding principle of this research present herself contextualizes is the perspective of that the intensification of urbanization in modernity had caused several problems socio environmental in the city of the present. The environmental perception is the central focus of this research in the city of Itabaiana/SE, hading as instrument of reflection, observational records involving a network of social implicate, cultural and environmental aspects, supplemented by questionnaires developed the light of a specific theoretical framework. Itabaiana especially in the region of transition from the rough sergipano, partially inserted into the polygon of drought. Analyzing the results, the population in check is aware of the implication of an improper management of solid waste with degradation in quality of life, to make good use of the area plant with trees of yours district and feel more annoyed with the noise and air pollution - smoke - than the water pollution, with the presence of sewage and of the garbage exposed.
\end{abstract}

Key words: Life quality, environment quality, environmental perception.

\section{RESUMEN}

El principio rector de esta investigación se contextualiza la opinión de que la intensificación del desarrollo moderno en los problemas sociales causados en la ciudad del presente. La percepción del medio ambiente es el tema central de esta investigación en la ciudad de Itabaiana / SE, y como herramientas para la reflexión, la participación de los registros de observación de una red social, cultural y los aspectos ambientales, complementados por los cuestionarios desarrollados a la luz de un determinado marco teórico. Itabaiana se destaca en la región de transición de las zonas rurales Sergipe, parcialmente insertada en el polígono de la sequía. Analizando los resultados, la población bajo control es consciente de las consecuencias de un manejo inadecuado de los residuos sólidos con la degradación de la calidad de vida, disfrutar de las zonas boscosas y los vecindarios se sienten más molestos con el ruido y la contaminación del aire -- humo - que la contaminación del agua, con la presencia de aguas residuales y la basura expuesta.

Palabras-clave: Calidad de vida, calidad ambiental, percepción social-ambiental.

\section{INTRODUÇÃO}

O despertar para o novo relacionamento entre os homens e seu meio ambiente alcança, com intensidades diferenciadas, cada continente, país, região e lugar do mundo, na medida em que no meio acadêmico, intelectual e nos diversos organismos da pesquisa surgem novas indagações a partir do resgate de temas tradicionais ou da introdução de novas abordagens.

Nessa perspectiva, os geógrafos encontram-se instigados a responder aos desafios voltados para a compreensão das questões ambientais. Os estudos geográficos sobre meio ambiente apon- 
tam a importância que a percepção do espaço assume quando se quer explicar fatos sob a ótica da ciência geográfica.

O princípio norteador da presente pesquisa se contextualiza na perspectiva de que a intensificação da urbanização na modernidade causou alguns problemas relacionados à qualidade e às condições ambientais e de vida na cidade do presente. A percepção da questão ambiental é uma resultante não somente do impacto objetivo das condições reais sobre os indivíduos, mas também da maneira como sua interveniência social e valores culturais agem na vivência dos mesmos impactos, onde o modelo de desenvolvimento que caracteriza a atual civilização conduz irremediavelmente à situação de degradação ambiental dos espaços urbanos, quer sejam eles grandes ou pequenos.

No presente artigo encontram-se apresentadas, e brevemente comentadas, algumas concepções acerca de propostas para a compreensão dos problemas socioambientais urbanos, uma vez que a vulnerabilidade envolve, assim como os riscos urbanos, uma rede de implicações sociais, econômicas, culturais, ambientais e políticas que estão diretamente vinculadas à condição de pobreza de representativa parcela da sociedade moderna.

Dessa forma, é importante que se faça uma análise combinada entre os fatores ambientais, sociais e culturais para alcançar o entendimento dos aspectos socioambientais de uma dada localidade. Este fato torna-se relevante para o estabelecimento de medidas que ofereçam condições dignas de vida à população.

Assim, o indicador subjetivo é foco central desta pesquisa, uma vez que a percepção que os indivíduos têm da qualidade de vida e ambiental é muito diferente de pessoa para pessoa, e de estrato social para estrato social. Logo, esta pesquisa teve como objetivo principal analisar a percepção dos cidadãos em relação à qualidade ambiental e de vida na cidade de Itabaiana/SE, buscando caracterizar a percepção dos citadinos no tocante a disposição da infra-estrutura socioambiental.

Para efetivação desta pesquisa realizou-se um trabalho de campo efetivado com a aplicação de questionários dentre a população residente na cidade de Itabaiana/SE. Foram analisados diversos temas no sentido de elucidar a percepção dos moradores em relação aos problemas ambientais urbanos, os quais estão ligados à qualidade socioambiental da cidade.

\section{O SISTEMA SOCIOAMBIENTAL URBANO}

A imagem da cidade hoje reproduz um debate sobre a interação entre a sociedade e a natureza à luz da discussão ambiental em decorrência da relação entre o natural e o social que produz o espaço geográfico.

Nesse sentido, "a cidade, não é somente uma construção humana; ela é esta construção somada a todo um suporte que a precedeu - Natureza - mais as atividades humanas" (MENDONÇA, 2004, p. 185). Resultado de tal construção surge ambientes urbanos com dimensões diferentes para o desenvolvimento humano, seja através da boa condição ou a partir de ambientes desagradáveis e altamente problemáticos, os quais representam grandes porções do espaço das cidades.

$\mathrm{E}$, ainda, antes de qualquer reflexão é necessário compreender que qualidade de vida não é apenas um fator construído através do cruzamento de elementos do quadro físico, econômico e humano. Ela trás subjetividades que superam a permanente necessidade de interação homem-natureza. Assim, na atualidade é preciso que a noção de qualidade de vida supere a visão higienista do século XIX e aponte para outras alternativas.

Ao longo da história das cidades criaram-se também debates, concepções e percepções diversas sobre a urbanização das cidades, porém no presente é importante observá-la através do aspecto interativo ou como um campo inter-multi-transdisciplinar, pois "o horizonte histórico-cultural deste debate está irremediavelmente atravessado por uma multiplicidade de interesses e projetos sociais que vão disputar diferentes interpretações sobre o ambiental" (GUIMARÃES, 2003, p. 81). 
A urbanização demonstra singularidades, principalmente em função dos estágios diferenciados do desenvolvimento econômico. Dessa forma, nos países que alcançaram um aprimoramento econômico e tecnológico mais cedo na modernidade, verificou-se um melhor ordenamento dos espaços urbanos, enquanto em países nos quais a organização social, política e econômica foi tardia o processo de desenvolvimento das cidades apresentou e apresenta problemas sócioambientais complexos e de difícil resolução. Tal fato traduz que nesses países "a dinâmica da urbanização pela expansão de áreas suburbanas produziu um ambiente urbano segregado e altamente degradado, com efeitos muito graves sobre a qualidade de vida da população" (JACOBI, 2004, p.172).

Por isso é necessário acontecer uma evolução do conceito de ambiente urbano a partir daquilo que é proposto pelo estudo do Sistema Socioambiental Urbano (MENDONÇA, 2004), o qual põe em evidencia a solução dos problemas sócioambientais urbanos, sob um ponto de vista integrador e abrangente. É assim em decorrência da instalação de um modelo de desenvolvimento paradoxal que mostra que mesmo diante de um amplo aparato tecnológico, uma significativa parcela da humanidade vivencia constantemente uma existência de pobre a miserável, desprovida das mínimas condições de vida digna e bastante vulnerável a catástrofes naturais.

Nesta perspectiva Guimarães (2003, p. 84) ressalva que "o modelo em questão prima pelos interesses privados (econômicos) frente aos bens coletivos (meio ambiente), consubstanciando-se em uma visão antropocêntrica de mundo, gerador de fortes impactos socioambientais".

A urbanização demonstra singularidades, principalmente em função dos estágios diferenciados do desenvolvimento econômico. Dessa forma, nos países que alcançaram um aprimoramento econômico e tecnológico mais cedo na modernidade, verificou-se um melhor ordenamento dos espaços urbanos, enquanto em países nos quais a organização social, política e econômica foi tardia o processo de desenvolvimento das cidades apresentou e apresenta problemas sócioambientais complexos e de difícil resolução.

Intervir na cidade a partir de uma perspectiva conjuntiva e da solução dos problemas socioambientais requer uma instalação de uma postura aberta de estudiosos, urbanistas e gestores urbanos, rompendo-se com a visão de estudo da cidade fruto da forma positivista de separação dos campos do conhecimento que a coloca em direção da abordagem das ciências humanas e sociais em detrimento da análise da natureza na cidade.

Umas das primeiras iniciativas que tratou a cidade sob um ponto de vista sistêmico, abordando o clima, um dos elementos formadores da cidade foi MONTEIRO em 1976 com a construção do Sistema Clima Urbano, mostrando que a cidade é fruto de um campo de interações ente a natureza e a sociedade (MONTEIRO \& MENDONÇA, 2003).

É nesta perspectiva que a concepção de ambiente urbano se desenvolve, uma vez que, todo um complexo fluxo de matéria e energia, de origem natural e/ou produto da ação humana, interage permanentemente no contexto urbano e dinamiza as formas com que se manifestam os elementos da natureza e da sociedade na cidade, formando a materialidade urbana (MENDONÇA, 2004).

Assim o ambiente urbano é resultado da interação da natureza na cidade e a sociedade na cidade. A primeira representando um somatório do relevo, ar, água, vegetação e solo, e a segunda composta pela habitação, indústria, comércio, serviços, transporte e lazer; configurando-se o ambiente urbano que é tido como resultado desta complexa interação.

É necessário ressaltar a questão da diversidade escalar da manifestação dos problemas ambientais urbano, lugar, bairro, setor, cidade, município, bacia hidrográfica, região, país, uma vez que a análise do ambiente urbano deve partir do contexto no qual se desenvolve.

O Sistema Ambiental Urbano é constituído pelo Subsistema Natural e pelo Subsistema Construído-habitação, indústria, comércio e serviços, transporte e lazer- (formadores do input) e pelo Subsistema Social (atributos do sistema) no qual se estabelece a dinâmica do sistema (dinâmica da natureza e sociedade) através das ações humanas, onde os problemas socioambientais urbanos surgem da interação entre os três subsistemas e subsubsistemas (formadores do output). 
Nesse sistema socioambiental os problemas urbanos de interesse, análise e intervenções são: degradação e poluição do ar, relevo, água, solo e vegetação; resíduos sólidos urbanos; inundações, deslizamentos, erosão; ocupações irregulares, invasões, favelamentos; fome, miséria, doenças transmissíveis. A solução de tais vulnerabilidades implicará de forma direta na qualidade de vida das populações envolvidas, possibilitando uma modificação do input, dos atributos e do output do sistema socioambiental urbano.

Logo, "os problemas ambientais que ocorrem nas cidades são, por princípio, problemas socioambientais, pois a cidade é o mais claro exemplo do espaço onde a interação entre a Natureza e a Sociedade se concretizam" (MENDONÇA, 2004, p.204-205).

\section{Percepção socioambiental dos citadinos de Itabaiana-SE}

Perceber significa adquirir conhecimentos de, pelos sentidos, ao passo em que o termo percepção remete-se ao ato, efeito ou faculdade de perceber (AURÉLIO, 1999). Ribeiro (2004) enfatiza o conceito afirmando que perceber não é um ato dependente apenas do ambiente em si, pois o que o individuo percebe nem sempre é o que o ambiente é, mas o que os seus sentidos apreendem a partir de seu filtro cultural.

Dessa forma, a percepção envolve a vida social, isto é, os significados e os valores das coisas percebidas decorrem de nossa sociedade e do modo como nela as coisas e as pessoas recebem valor ou função, por isso os indivíduos sentem e percebem formas, isto é, totalidades estruturadas dotadas de significação diante da realidade vivenciada pelos mesmos.

O estilo de vida de um povo é a soma de suas atividades econômicas, sociais e ultraterrenas. Estas atividades geram padrões espaciais; requerem formas arquitetônicas e ambientes materiais que depois de terminados influenciam o padrão das atividades (TUAN, 1980).

A percepção para a ciência geográfica ressalta o estudo das paisagens e do espaço vivido pelo homem, pois a questão do espaço vivenciado em sua percepção tornou-se um elemento tanto de qualidade de vida percebida ou não, como de aceitação imposta pela questão da sobrevivência neste espaço, ou seja, seu meio ambiente. Logo, "assim como variam as percepções e as imagens mentais a respeito da qualidade ambiental, também variam as atitudes e os valores atribuídos ao meio ambiente" (OLIVEIRA, 2002, p. 47).

O termo percepção ambiental inclui não apenas as percepções bio-fisiológicas, mas também as imagens que formamos mentalmente sobre o mundo vivido. Nossas memórias, experiências, predileções, interpretações, atitudes e expectativas.

Nesse sentido o estudo da cidade surge como um fenômeno experenciado pelo morador, que percebe a qualidade do meio ambiente que o cerca. Aqui "o ambiente como uma realidade complexa é aquele que interconecta o que está fora e dentro da escola, está na realidade local e global, está no pátio escolar e na reserva ambiental, está no social e no ambiental" (GUIMARÃES, 2003, p. 100).

Itabaiana é a terceira cidade de destaque do interior sergipano. Situa-se na latitude de $10^{\circ} 41^{\prime} 06^{\prime \prime}$ Sul e de longitude de $37^{\circ} 25^{\prime} 31^{\prime \prime}$ Oeste, centrado na faixa centro-ocidental do estado de Sergipe (figura 01). Ocupa uma extensão territorial de $336,9 \mathrm{~km}^{2}$, representando $1,53 \%$ do território sergipano. Possui 52 povoados e sua sede municipal distancia-se da capital do estado, Aracaju, em $56 \mathrm{~km}$.

A sede do município apresenta 15 bairros, em ordem: Anísio Amâncio De Oliveira, Bananeira, Centro, Dr. José Milton Machado, Mamede Paes Mendonça, Marcela, Marianga, Miguel Teles De Mendonça, Oviedo Teixeira, Queimadas, Riacho Doce, Rotary Clube, São Cristóvão, Serrano e Sítio Porto, estrutura presente no Plano Diretor Participativo De Itabaiana, 13 de dezembro de 2007. Contudo, apenas 12 áreas são bem definidas, enquanto duas estão agrupadas em dois outros espaços, que são: Os bairros Milton Machado e Oviedo Teixeira e os bairros Queimadas e Riacho Doce.

Assim, a exemplo das demais cidades brasileiras apresenta desigualdades sociais, refletindo na estruturação do espaço urbano, fruto de um processo geral de reprodução do sistema capitalista no qual está inserida. 
Durante o trabalho de campo foram estruturadas, a luz de um referencial teórico específico, algumas questões sobre noções básicas do meio ambiente, as quais viabilizaram a análise da percepção dos citadinos sobre ações cotidianas e responsabilidades ambientais que influenciam a qualidade socioambiental urbana municipal.

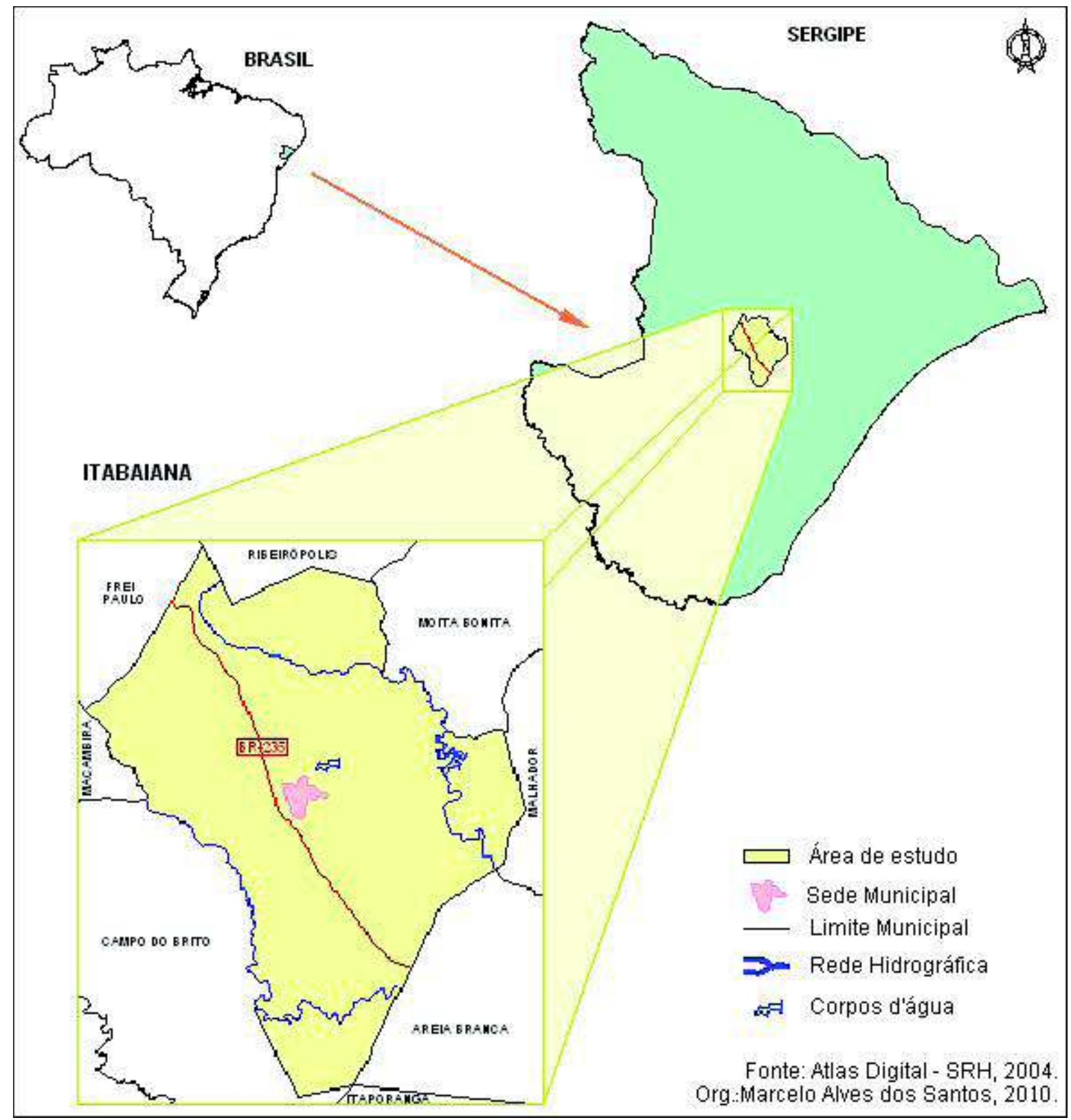

Figura 1 - Localização do município de Itabaiana/SE.

Fonte: Base cartográfica SEPLANTEC, 2004.

Organização: Cleane O. dos Santos e Marcelo A. dos Santos, 2008.

Cabe salientar que as questões da qualidade de vida e ambiental em Itabaiana estão vinculadas ao conjunto formado pela estrutura socioeconômica e, conseqüentemente, pela carência de consciência ambiental de uma significativa parcela da população e dos órgãos públicos que não proporcionam a comunidade acesso à educação ambiental.

No tocante ao nível de conhecimento sobre meio ambiente $7 \%$ afirmaram ter um grau muito baixo de compreensão sobre fatores ambientais ou até mesmo nem sabiam o que representa o meio ambiente, $47 \%$ da amostra disseram possuir um nível médio de conhecimento acerca do ambiente, 
seguidos de $22 \%$ que reconheceram possuir um nível alto de entendimento e $4 \%$ demonstraram ter um grau muito alto de conhecimento (figura 2).

Uma significativa parcela reconheceu que atividades do cotidiano causam algum dano ao meio ambiente quando: depositam óleo doméstico no esgoto, jogam lixo na rua e não realizam uma separação do lixo, usam meios de transporte para se locomover que liberam $\mathrm{CO} 2$ na atmosfera e produzem a poluição sonora, entre outros exemplos. Alguns não têm consciência alguma de qualquer prejuízo ao meio ambiente.

Analisando a percepção dos entrevistados acerca do conteúdo da Agenda 21, como um instrumento que prevê, entre outras melhorias: oferecer habitação adequada; promover o planejamento e o manejo sustentáveis do uso da terra; promover a existência integrada de infra-estrutura ambiental: água, saneamento, drenagem e manejo de resíduos e gerar o desenvolvimento dos recursos humanos e da capacitação institucional e técnica para o avanço dos assentamentos humanos, observamos, os seguintes resultados: $69 \%$ da amostra asseguraram nunca ter ouvido falar sobre o assunto, $22 \%$ disseram que já ouviram falar, mas que não sabe do que se trata e apenas $9 \%$ afirmaram saber o significado da Agenda 21 apontando para um instrumento de planejamento.

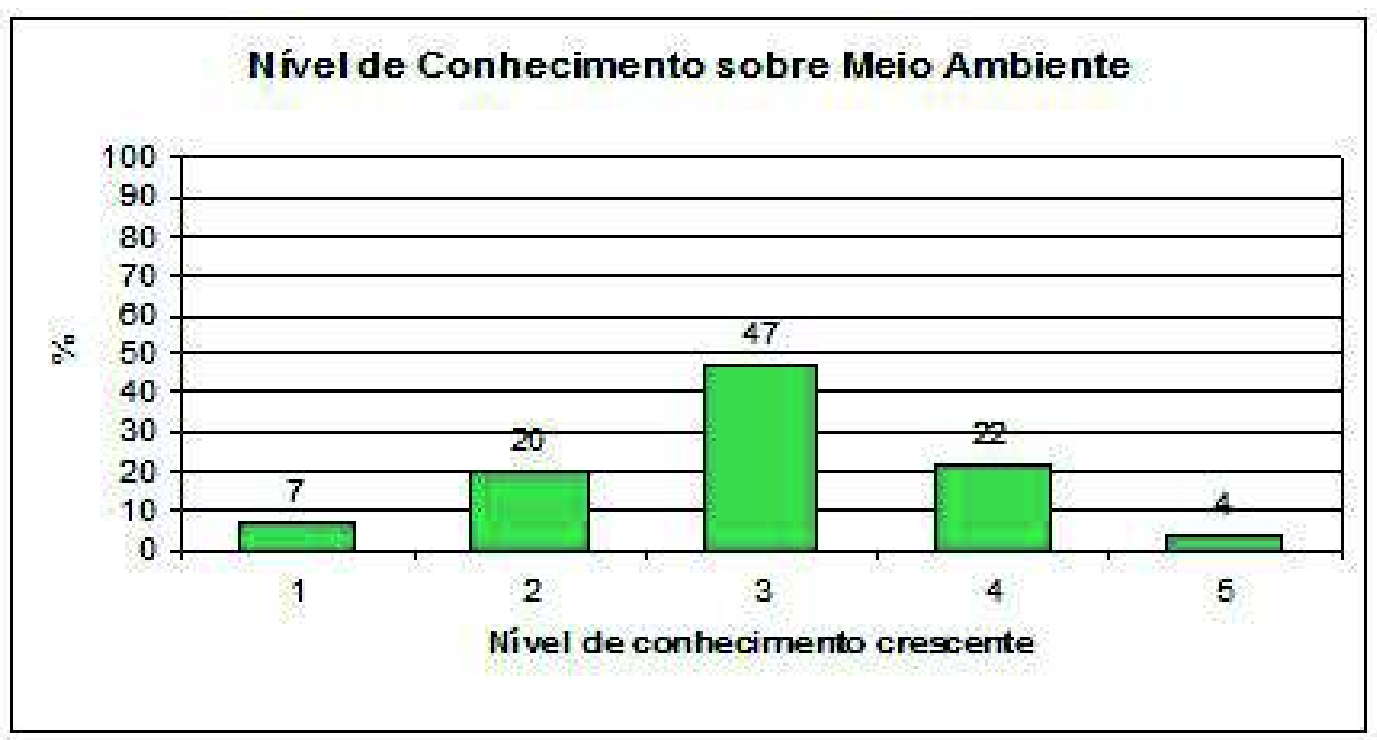

Figura 2 - Gráfico de Análise do nível de conhecimento sobre meio ambiente. Organização: Clêane Oliveira dos Santos, 2009.

Fonte: Questionários, 2009.

Os entrevistados ainda foram questionados acerca do nível de incômodo em relação a alguns problemas ambientais, tais como, poluição da água, poluição do ar, poluição sonora, poluição visual, lixo não acondicionado e esgotos não tratados. Para tanto o amplitude do incômodo foi avaliada a partir da escala compreendida entre um (nível muito baixo) e cinco (nível muito alto). Conforme a tabela 1 os maiores índices de incômodo estão relacionados à poluição sonora, ao lixo não acondicionado e aos esgotos não tratados, entretanto a poluição da água, a poluição visual e a poluição do ar são associados ao nível médio de incômodo.

Sobre a poluição sonora, a população alega que é provocada pelos carros de propagandas comerciais, sons de carros particulares e ainda pelas motocicletas. Pode-se afirmar que a poluição sonora é hoje, depois da poluição do ar e da água, o problema ambiental que afeta o maior número de pessoas. É perceptível o aumento da indisposição devido ao ruído e o prejuízo que isto tem causado ao homem no seu ambiente laboral e/ou ambiental. 
O nível de incomodo com a poluição da água foi referenciado pelos entrevistados como sendo em virtude da constante ocorrência de água suja que chega às residências através do sistema de abastecimento de água, distribuído pela companhia de Saneamento de Sergipe (DESO). O nível de mal estar em relação à poluição visual foi considerado baixo. 30\% dos entrevistados desconsideram.

A poluição do ar é reconhecida em função da poeira advinda de olarias e cerâmicas que estão localizadas no perímetro urbano da cidade, a exemplo do bairro Macela (figura 3), e da poluição no Bairro Serrano em decorrência do armazém do Café Novo Horizonte.

Tabela 1 - Percepção de incômodo em relação aos problemas ambientais.

\begin{tabular}{|c|c|c|c|c|c|}
\hline \multirow{2}{*}{$\begin{array}{c}\text { PROBLEMAS } \\
\text { AMBIENTAIS } \\
\end{array}$} & \multicolumn{5}{|c|}{ NÍVEL DE INCÔMODO CRESCENTE } \\
\hline & $\begin{array}{c}\text { Muito Baixo } \\
\%\end{array}$ & $\begin{array}{l}\text { Baixo } \\
\%\end{array}$ & $\begin{array}{c}\text { Médio } \\
\%\end{array}$ & $\begin{array}{l}\text { Alto } \\
\%\end{array}$ & $\begin{array}{c}\text { Muito Alto } \\
\%\end{array}$ \\
\hline Poluição sonora & 4 & 10 & 13 & 18 & 55 \\
\hline Poluição da água & 7 & 21 & 32 & 14 & 26 \\
\hline Poluição visual & 12 & 30 & 24 & 21 & 13 \\
\hline Poluição do ar & 13 & 17 & 35 & 17 & 18 \\
\hline Lixo não acondicionado & 5 & 12 & 16 & 23 & 44 \\
\hline Esgotos não tratados & 8 & 20 & 19 & 18 & 35 \\
\hline
\end{tabular}

Organização: Clêane Oliveira dos Santos, 2009.

Fonte: Questionários, 2009.

No quesito saneamento ambiental, pode-se verificar a problemática que a presença dos resíduos sólidos urbanos provoca constitui-se num desafio público a ser enfrentado na estruturação do setor. A discussão atual dos resíduos sólidos está relacionada com sua produção e disposição final, enquanto a implicação da gestão inadequada dos resíduos sólidos é refletida na degradação do solo, na poluição das águas e do ar e na saúde pública.

$\mathrm{Na}$ maioria das cidades, os resíduos produzidos não recebem tratamento e nem destino final adequados, devido à falta de recursos financeiros e humanos, à falta de planejamento do setor de limpeza urbana e às dificuldades inerentes ao sistema de gerenciamento integrado dos resíduos. Não restam dúvidas que os resíduos sólidos são considerados um dos maiores problemas encontrados na sociedade vigente. Os inconvenientes gerados pela falta de tratamento e pela disposição inadequada têm distanciado cada vez mais a sustentabilidade urbana.

Dessa forma, a implicação da gestão imprópria dos resíduos sólidos é refletida na degradação do solo, na poluição das águas e do ar e na saúde pública. De acordo com o UNICEF (Fundo das Nações Unidas para a Infância), no Brasil, mais de 40 mil pessoas viviam diretamente da catação de resíduos em lixões e mais de 30 mil vivem da catação nas ruas da cidade, sendo a única forma de rendimento dessas pessoas. Calculava-se que em alguns casos a participação de crianças e de adolescentes representasse 50\% dos catadores (BRASIL, 2002).

Assim, de acordo com a PNSA (Pesquisa Nacional de Saneamento Ambiental) realizada pelo IBGE no ano de 2000, das cerca de 230 mil toneladas diárias de lixo coletado no Brasil, 58, 25 tem como destino vazadouros a céu aberto e aterros controlados, isto é, mais da metade dos resíduos recolhidos não recebe destinação adequada.

Em Itabaiana, como no Brasil, a prática do desperdício, associada à cultura e ao consumo de descartáveis, aumenta a geração de resíduos e a forma que esses resíduos vinham sendo coletados e destinados. 


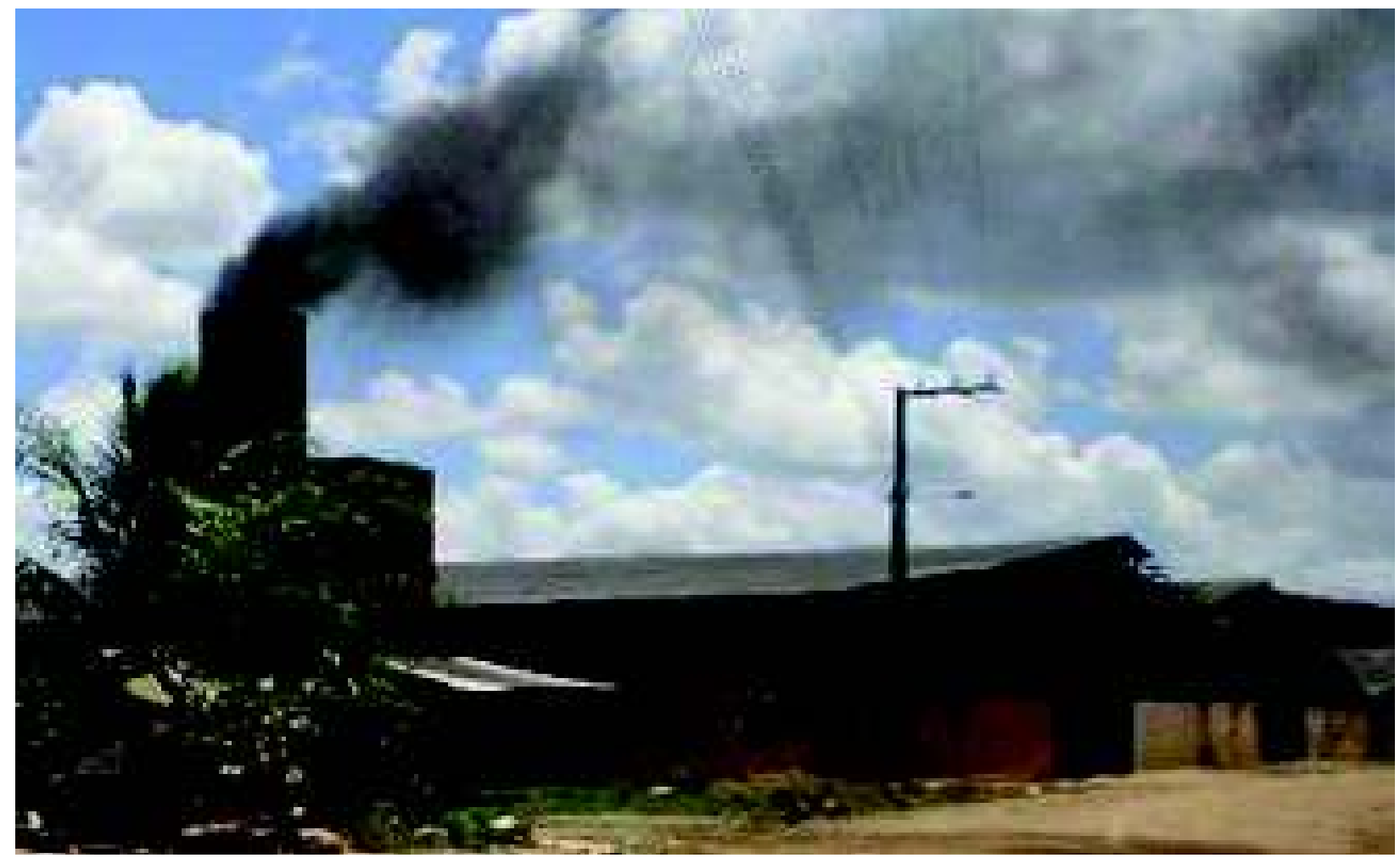

Figura 3 - Vista de uma cerâmica localizada no bairro Macela Foto: Clêane Oliveira dos Santos, 2008

Questões relativas ao lixo, tratamento e acondicionamento, mereceram atenção na pesquisa. Entrevistados no trabalho de campo, complementado por leituras de outras realidades, e com base em visitas locais, registradas em fotografias, pode-se afirmar que na cidade existe muito lixo depositado nas ruas e, principalmente, em terrenos baldios a exemplo das figuras 4 indicativa de dois bairros distintos da cidade, um central e outro periférico, respectivamente, mas que refletem o mesmo vício.

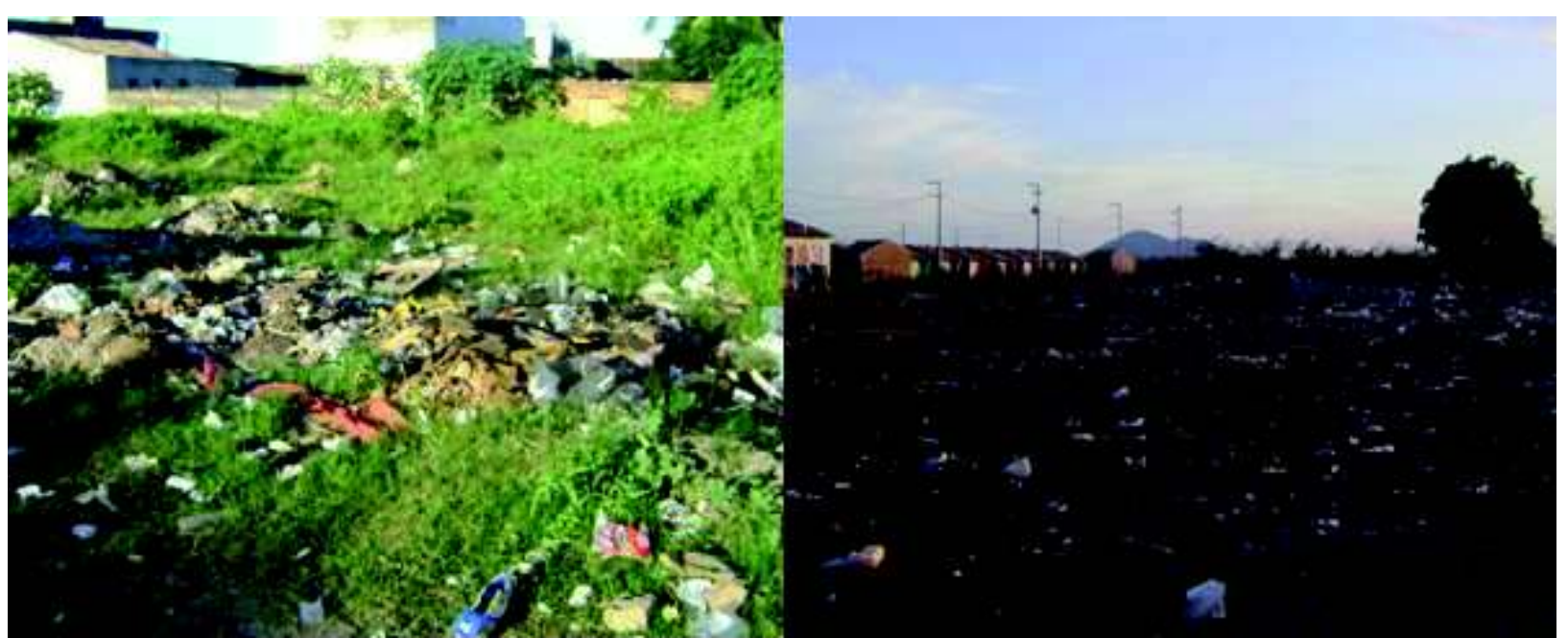

Figura 4 - Lixo doméstico depositado pela população em terreno baldio no bairro Centro (Esquerda) e no bairro São Cristóvão (Direita).

Foto: Clêane Oliveira dos Santos, 2009.

O nível de incômodo em relação aos esgotos não tratados, também, foi classificado como muito alto, onde $35 \%$ afirmaram sentir-se incomodados com o mau cheiro ocasionado pelo deficiente sistema de algumas localidades da cidade, principalmente, em bairros periféricos. 
Dado significativo diz respeito a questão formulada sobre aceitar ou não um determinado nível de poluição na cidade se tal fato redundasse em uma maior oferta de emprego. Verifica-se que $65 \%$ disseram que não, que o meio ambiente não deve ser prejudicado de forma alguma, $24 \%$ responderam que sim, pois ter emprego é mais importante e $11 \%$ afirmaram que depende, pois a oferta de emprego iria proporcionar maior qualidade de vida ou que dependeria do grau de poluição, pois o progresso da cidade seria mais significativo.

Em Itabaiana, a função do capital muitas vezes sobre julga o meio ambiente circundante, uma vez que a cidade possui um caráter ou função voltada para o comércio. A construção da BR-235 e de outras vias que a intercalam, contribuiu para impulsionar a fixação de suas atividades econômicas, principalmente no que se refere às atividades do segmento terciário e primário. $\mathrm{O}$ setor primário da economia mostra crescimento em função da maior articulação do meio rural-urbano a nível municipal, estadual e mesmo, nacional, como também, a partir da institucionalização de políticas públicas e crédito rural, que consolidaram a atividade agrícola no município, tornando-o ponto de referência de produção de olerícolas e representativo centro distribuidor de hortifrutigranjeiros.

Por isso, observa-se que a cidade transformou-se em entreposto comercial de itens produzidos em seu próprio município como também de outros estados. Fato que corroborou numa maior articulação campo-cidade dentro do município, como entre outras cidades-campos estaduais e nacionais. Dessa maneira, as preocupações com o meio ambiente são relegadas para o segundo plano e a questão da renda, pode-se dizer que a questão da identidade comercial, que os cidadãos itabaianenses defendem como afinco, assume um contexto mais importante para o desenvolvimento da cidade, uma vez que a distribuição do PIB destaca-se o setor de serviços com $\mathrm{R} \$ 422.229$, seguido do setor industrial com R\$57.076 e da agropecuária com R\$22.458 (IBGE, 2006).

Na pesquisa foram realizados alguns questionamentos ainda, sobre a percepção da importância, da intensidade e da interferência da arborização no conforto térmico da cidade. A arborização é um fator considerável para a qualidade de vida humana.

A sede municipal de Itabaiana destaca-se também em função da localização geográfica, segundo a Secretaria de Estado do Planejamento e da Ciência e Tecnologia (SEPLANTEC,1997), parcialmente inserida no polígono das secas, configurando-se numa região de transição climática, o agreste sergipano, fato que a torna peculiar no contexto de Sergipe, pois apresenta vulnerabilidades ambientais.

Segundo Pinto (2006), a idéia do clima de um lugar, que dá origem à expectativa de seu próprio comportamento, é elaborada pela tradição, representada pela transmissão oral de usos e costumes, aliada à vivência do dia a dia das pessoas. Logo, a perspectiva de relação e dependência dos seres vivos em respeito ao clima, a capacidade de adaptação e o emprego de tecnologias para uso mais racional de recursos disponíveis, atesta que o homem é de fato um ser integrado ao meio.

É importante destacar que a maior parte dos municípios de Sergipe apresenta deficiência hídrica quase todo o ano, principalmente na primavera e verão, assim, no município em julgo não acontece diferente, ocorrendo excedentes de chuvas nos meses de maio, junho e julho, período em que se observa um decréscimo de temperatura que se prolonga até final do mês de agosto. Nesse sentido, a sensação de conforto térmico da área urbana municipal está diretamente vinculada aos períodos oscilação de temperatura e, também, a expansão da estrutura urbana que vem se acentuando.

É sabido que a intensa e crescente urbanização que vem ocorrendo nas cidades tem modificado os aspectos do clima local e conseqüentemente prejudicado o conforto térmico. A desordenada ocupação do solo, o aumento de áreas construídas e o adensamento populacional, associados à redução de espaços verdes intra-urbanos e à poluição atmosférica, têm provocado alterações no microclima das cidades, tais como elevação da temperatura e umidade do ar mudança da direção e velocidade dos ventos. 
Nessa perspectiva se destaca a importância das áreas verdes e sua influência no microclima urbano, a fim de mitigar os efeitos prejudiciais da urbanização e na melhora das condições ambientais em áreas urbanizadas.

Quando avaliados acerca da importância da arborização numa cidade, 38\% apontaram a escala máxima, considerando uma escala de 1 a 5 em nível de importância crescente. Esse fato pode estar ligado à questão do desconforto térmico que é sentido na cidade, principalmente, no bairro centro onde se dá um maior fluxo de pessoas e tráfego de automóveis de pequeno, médio e grande porte, sendo enfática nos dias de feira, quando se concentram cerca de 25.000 pessoas nessa área, ou ainda nas quintas-feiras, devido à concentração de veículos para embarque e desembarque de mercadorias nos Largos São Antônio e Largo José do Prado Franco. Logo, em virtude de tantos fluxos há períodos do dia, onde o calor torna-se acentuado.

$\mathrm{Na}$ cidade de Itabaiana, assim como nas demais cidades de pequeno e médio porte, as árvores estão distribuídas em áreas pontuais da cidade, especificamente nos canteiros das principais avenidas e nas praças localizadas tanto no centro da cidade quanto em bairros mais afastados.

Na cidade em pauta foram contabilizadas doze praças: Praça Fausto Cardoso, João pessoa, General João Perreira, São Luiz, João Marcelo, Lafaete Noronha, Padre Gumercindo, Oliveira, Vesta Maria de Góis, Frei Fidelis, Jubal de Carvalho, Calçadão Francisco Teles de Mendonça.

É importante ressaltar que apesar da existência de um significativo número de praças na cidade, verifica-se que em algumas delas não existe arborização, observando-se no máximo gramados e pequenas plantas. Tal fato se apresenta nas praças localizadas em bairros periféricos da cidade, fotografada na figura 5 .

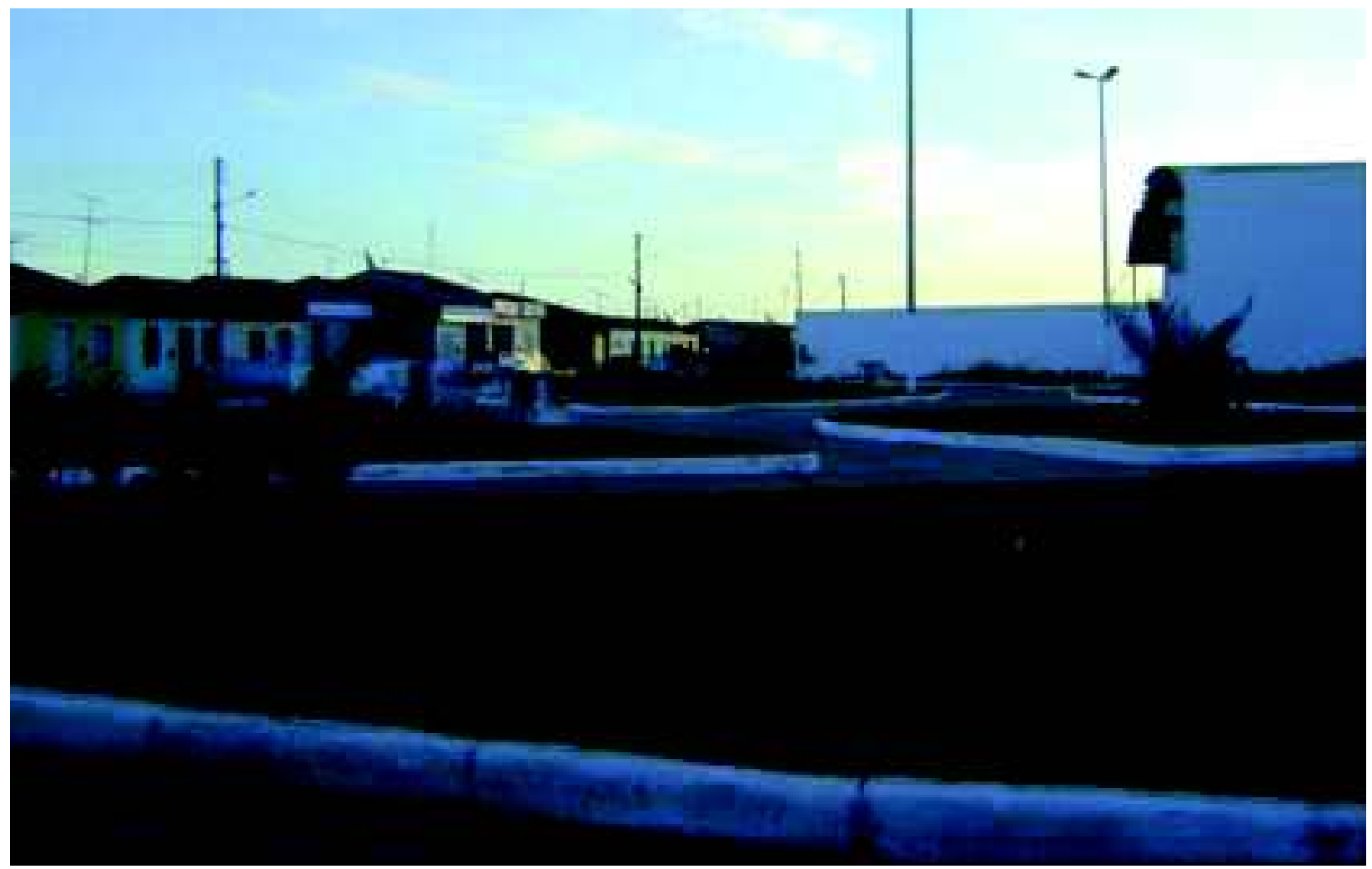

Figura 5 - Vista da Praça do bairro São Cristóvão. Foto: Clêane O. dos Santos, 2009

A arborização na cidade em questão é o componente ambiental mais visível, contudo a população ainda não reconhece a importância da conservação das árvores para a qualidade ambiental do espaço vivido na cidade, uma vez que são nas praças, principalmente, que se efetivam as relações sócio-culturais dos itabaianenses. 
O espaço ocupado por áreas verdes nas cidades vem reduzindo afetando não somente a paisagem da cidade, mas, também, a qualidade ambiental, representando alterações significativas nos padrões de circulação das massas de ar, podendo levar a possíveis mudanças no seu microclima, e no sistema de drenagem local. No entanto, essas áreas são importantes, dentre outros motivos, porque permitem que a água da chuva penetre no solo, alimentando o lençol freático, evitando que esta água se acumule sobre a área coberta por materiais impermeáveis e cause transtornos socioambientais.

Assim, o espaço construído e a insuficiência de áreas verdes no município atuam sobre a temperatura e a umidade. Além disso, a construção e substituição da superfície natural por um conjunto de construções de imóveis aumentam a rugosidade, cujos efeitos mais diretos são: a redução da velocidade do vento e aumento da turbulência.

Logo, é o grande percentual de cobertura do solo da cidade por asfalto e cimento, a causa de problemas freqüentes em épocas de chuvas, como as enchentes. Principalmente, em épocas de chuva é comum percebermos o dano causado pelos alagamentos em vários pontos de bairros distintos.

\section{CONSIDERAÇÕES FINAIS}

De acordo com o levantamento e análise dos dados considera-se que a percepção da população em relação à qualidade de vida e ambiental da cidade de Itabaiana é significativa em virtude do nível de respostas dadas as questões presentes no questionário.

As diferenças perceptivas foram marcantes no cotidiano do bairro como elemento de observação e restrito a sua moradia, seus problemas e suas qualidades. Não havendo uma preocupação ampla de questões urbanas como um todo e da possibilidade de interação de problemas ou mesmo de reflexos de outros bairros em sua qualidade de vida.

É reconhecido pelos munícipes que a cidade precisa desenvolver um sistema de coleta seletiva de lixo, iniciando com o reparo de lixeiras comuns que existem nas praças públicas da cidade, implantado a estrutura necessária de coletores seletivos não somente nas praças, mas também nas principais ruas da cidade. Além disso, denunciam que na cidade não existe um local de depósito de óleo doméstico, de resíduos radioativos, pilhas e baterias de telefone celular, de resíduos com poder contaminante provenientes das oficinas de automóveis. Aqui, demonstram conhecimento de carências que contribuem para a efetivação da poluição do meio ambiente.

Observou-se também que o crescimento e expansão populacional e espacial da cidade vinculase ao crescente desconforto térmico que tem se intensificado em vista da pavimentação da cidade, especialmente, no bairro centro. Desse modo, sabem que se deve incentivar a plantação e conservação de árvores, tanto nas praças como nas calçadas e canteiros das ruas da cidade, pois funciona como um amenizador térmico do calor dos trópicos, beneficiando, outrossim, a qualidade de vida e ambiental da cidade.

Vale ressaltar que a identidade cultural é um processo de reconhecimento que o sujeito social realiza ao viver numa cultura e assume como algo próprio, os valores característicos de uma determinada cultura, ou seja, é a forma como os sujeitos sociais incorporam e expressam - através da vivência - os elementos da cultura dos grupos do qual fazem parte.

Portanto, de forma geral, vinculados ou não à cultura local, dados da amostragem apontam para a reflexão da falta de preocupação da maioria dos indivíduos envolvidos na pesquisa para com as questões socioambientais, uma vez que a identidade cultural marcante da população está vinculada, especificamente, a questão do desenvolvimento econômico/comercial de Itabaiana.

\section{REFERÊNCIA BIBLIOGRÁFICA}

BRASIL, Ministério de Meio Ambiente. Consumo Sustentável: manual de educação. Brasília: Consumers International/MMA/IDC, 2002. $144 \mathrm{p}$.

Mercator - volume 9, número 18, 2010: jan./abr. 
FERREIRA, Aurélio Buarque de Holanda. Dicionário Aurélio eletrônico: Século XXI. Rio de Janeiro: Nova Fronteira/Lexicon Informática, 1999.

IBGE. Pesquisa Nacional de Saneamento Básico 2000.

IBGE. Itabaiana. Estrutura Empresarial, 2006

JACOBI, P. Impactos sócioambientais urbanos: Do risco à busca da sustentabilidade. In: MENDONÇA, Francisco (org.). Impactos sócioambientais urbanos. Curitiba: Ed. UFPR, 2004, pp. 169-184.

MENDONÇA, Francisco. Sistema ambiental urbano: Uma abordagem dos problemas sócioambientais da cidade. In: MENDONÇA, Francisco. (org.). Impactos sócioambientais urbanos. Curitiba: Ed. UFPR, 2004, pp. 185-208.

MONTEIRO C. A. de F., MENDONÇA, F. Clima Urbano. São Paulo: Contexto, 2003. 192p.

OLIVEIRA, Lívia de. A percepção da qualidade ambiental. In: Caderno de Geografia. Belo Horizonte: PUC, 2002, v. 12, nº.18.

PINTO, J. E. Derivações antropogênicas do clima no espaço agrário de Sergipe: um ensaio. Simpósio de Climatologia Geográfica, 7, 2006, Rondonópolis, MT. Anais..., Rondonópolis/ MT: UFMT, 2006.

RIBEIRO, L. M. Sobre percepção: contribuição da historia para a educação ambiental. OLAM - Ciência \& Tecnologia, Rio Claro/SP, v. 4, $\mathrm{n}^{\circ}$ 1, 2004.

SECRETARIA DE ESTADO DO PLANEJAMENTO E DA CIÊNCIA E TECNOLOGIA - SEPLANTEC. Perfis Municipais, Itabaiana. Aracaju, 1997. 75v.

TUAN, Yi-Fu. Topofilia: Um estudo da percepção, atitudes e valores do meio ambiente. São Paulo: Difel, 1980.

Trabalho enviado em janeiro de 2010

Trabalho aceito em abril de 2010 